\title{
Delay Between Shaking and Actuation of a Hydrofluoroalkane Fluticasone Pressurized Metered-Dose Inhaler
}

\author{
Ariel Berlinski MD, Dirk von Hollen, John N Pritchard PhD, and Ross HM Hatley PhD
}

\begin{abstract}
BACKGROUND: Inhaled corticosteroids are used to treat pediatric asthma. The shaking of a pressurized metered-dose inhaler (pMDI) is required to ensure consistency of emitted dose. Delays between shaking and actuating the pMDI are frequent during administration of aerosols to children where a valved holding chamber is used. METHODS: In a recent clinical trial, we used a monitoring device to record shaking and actuation of the pMDI and the inhalation profiles of children with asthma while they were inhaling fluticasone hydrofluoroalkane from a valved holding chamber onto an external filter. During the procedure, in vitro and transport samples were generated without a delay between shaking and actuating the pMDI. Emitted dose, expressed as percentage of ex-actuator nominal dose, obtained from the second actuation following a recorded shakeactuation interval for subjects and from in vitro/transport samples (no delay) were compared. RESULTS: The mean emitted dose was 158.6\% (95\% CI 150.1-167.2\%) (subjects) and 106.8\% (95\% CI 104.7-108.9\%) (in vitro + transport) of the ex-actuator nominal dose $(P<.001)$. The mean delay between shaking and actuating the pMDI was $12.9 \mathrm{~s}(95 \%$ CI 11.9-13.9 s) for the subject samples. A strong correlation was observed between shake and actuation delay and the emitted dose of the second actuation following the delay (Spearman correlation coefficient $=0.61$ ). A 10-, 20-, and 30-s delay resulted in an emitted dose of the second actuation following the delay of 147,187 , and $227 \%$ of the ex-actuator nominal dose, respectively. CONCLUSIONS: Delays between shaking and actuating a corticosteroid suspension pMDI resulted in an increase in the emitted dose of the second actuation following the delay. This can be a common occurrence when doses are administered by a caregiver to a patient via a holding chamber. This should be addressed by practitioners educating patients and parents on proper inhaler use. (ClinicalTrials.gov registration NCT01714063.) Key words: fluticasone; suspension; drug output; delay; valved holding chamber; metered-dose inhaler; shaking; actuation. [Respir Care 2018;63(3):289-293. @ 2018 Daedalus Enterprises]
\end{abstract}

\section{Introduction}

Asthma is a highly prevalent condition in pediatric patients. ${ }^{1}$ Inhaled corticosteroids are the most commonly used

Dr Berlinski is affiliated with the Pulmonology Section, Department of Pediatrics, University of Arkansas for Medical Sciences, College of Medicine/Pediatric Aerosol Research Laboratory, Little Rock, Arkansas. Mr von Hollen is affiliated with Respironics, a Philips Healthcare Company, Murrysville, Pennsylvania. Mr Pritchard and Mr Hatley are affiliated with Respironics Respiratory Drug Delivery (UK), a Business of Philips Electronics UK, Chichester, United Kingdom.

Dr Berlinski presented a version of this work at the 2015 International Society for Aerosols in Medicine Meeting, held May 31 to June 3, 2015, in Munich, Germany.

This was an investigator-initiated study supported in part by Respironics. preventive medications in asthma care. ${ }^{1}$ Although several delivery devices are available, pressurized metered-dose inhalers (pMDIs) with valved holding chambers are fre-

\footnotetext{
Dr Berlinski has disclosed relationships with AbbVie, Anthera, Aptalis Pharma, Cempra, Janssen Research and Development, Gilead, the National Institutes of Health, Novartis, the Therapeutic Development Network, Vertex, and the International Pharmaceutical Aerosol Consortium on Regulation and Science. Mr Hatley and Mr Pritchard are employees of Respironics Respiratory Drug Delivery (UK). Mr von Hollen is an employee of Respironics USA.
}

Correspondence: Ariel Berlinski MD, Pediatric Pulmonology Section, 1 Children's Way, Slot 512-17, Little Rock, AR 72202. E-mail: berlinskiariel@uams.edu.

DOI: $10.4187 /$ respcare. 05782 
quently used to deliver inhaled corticosteroids to children. ${ }^{2}$ Delivery of aerosols in children is more challenging than in adults due to lack of cooperation. ${ }^{3}$ This could result in a significant time between shaking the inhaler, settling the child and applying the mask, and actuating the inhaler. Inhaled corticosteroids in pMDIs are available either as solutions or suspensions. The latter have to be shaken before actuation to homogenize the drug and propellant. The composition of the dose present in the metering chamber ready to use is dependent on the previous shaking time and operation of the canister. ${ }^{4}$

It is not uncommon for a lack of cooperation by the child to result in a delay between the shaking of the pMDI and its actuation during administration of a pMDI via valved holding chamber to children. However, data regarding the effect of the delay on emitted dose is limited to in vitro studies. $^{5}$ In a recent study in children with asthma, we compared the dose of fluticasone emitted from a valved holding chamber when pMDI actuation was coordinated with the onset of inhalation or when the pMDI actuation was uncoordinated, and the pMDI was actuated during exhalation. ${ }^{6}$ In that study, a monitoring device was used to record shaking and actuation of the device. Therefore, we were able to evaluate the effect of a delay between shaking and actuation on fluticasone output. We speculate that due to a mismatch in density between the drug particles and propellant, settling or creaming of the suspension may occur after shaking and before the actuation occurs. This in turn may mean that the longer the delay, the higher the variance from the ex-actuator nominal dose of emitted dose will be. The purpose of this study was to evaluate the effect of a delay between shaking and actuation of a pMDI used with a nonelectrostatic valved holding chamber on the emitted dose of fluticasone hydrofluoroalkane.

\section{Methods}

The study was approved by the University of Arkansas institutional review board (approval 137456) and was registered at ClinicalTrials.gov (registration NCT01714063). ${ }^{6}$ Parents provided consent, and children $7 \mathrm{y}$ or older also provided assent. All procedures were performed by the principal investigator. The study was performed at Arkansas Children's Hospital (Little Rock, Arkansas). The study included clinically stable children with asthma age 5-8 y, who were prescribed an inhaled corticosteroid via pMDI and valved holding chamber and who either used or were able to use a mouthpiece. ${ }^{6}$ Patients unable to understand the instructions or with a clinically important respiratory illness in the 4 weeks before the study were excluded. ${ }^{6}$

The methodology of the trial has been reported previously. ${ }^{6}$ Briefly, the study began with an in vitro control run that included 5-s shaking and immediate actuation of a fluticasone pMDI (Flovent hydrofluoroalkane, $220 \mu \mathrm{g} / \mathrm{ac}-$

\section{QUICK LOOK}

\section{Current knowledge}

Currently, the instructions for use of corticosteroid suspension formulations, such as fluticasone hydrofluoroalkane, do not include any recommendation regarding the maximum accepted time interval between shaking and actuation of the canister. Settling of the suspension may occur if a delay occurs between shaking and actuation, thus affecting the emitted dose.

\section{What this paper contributes to our knowledge}

A delay between shaking and actuating of a corticosteroid suspension formulation resulted in a change of the amount of drug released by the pressurized metereddose inhaler in the second actuation following the delay. This phenomenon would lead to over- and underdosing, depending on the life of the canister. Manufacturers of pressurized metered-dose inhalers containing drugs formulated as suspensions should specify the maximum delay time between shaking and actuating that does not significantly affect the delivered dose.

tuation, GSK, Research Triangle Park, North Carolina) coupled to a valved holding chamber (OptiChamber Diamond, Respironics Respiratory Drug Delivery, Chichester, United Kingdom) and connected to a $30-\mathrm{L} / \mathrm{min}$ suction pump (Fig. 1A). A collecting filter was present between the valved holding chamber and the mouthpiece. Nine more puffs were actuated into the valve holding chamber under similar testing conditions. The chamber is made of transparent nonelectrostatic material, has low resistance inspiratory and expiratory valves, and has a volume of $145 \mathrm{~mL}$.

Next, using a new pMDI and valved holding chamber, subjects were randomized to perform 6 different experiments involving one puff of the pMDI inhaled onto the filter (Fig. 1B). The pMDI was actuated at the beginning of inhalation in 3 maneuvers and at the beginning of exhalation during the other 3 maneuvers. The study was completed with another in vitro run similar to the one done at the beginning. Three transport control samples of one puff each were generated after the final in vitro part and were included in the package corresponding to the samples of each subject. A data logger, developed by Philips Respironics, that recorded the shaking of the pMDI, the actuation, and the inhalation profile of the subjects was used. ${ }^{6}$ An example of the recorded data can be seen in Figure 2. The drug contained in the valved holding chamber, filter, and transport container was analyzed with a validated highperformance liquid chromatography method according to 


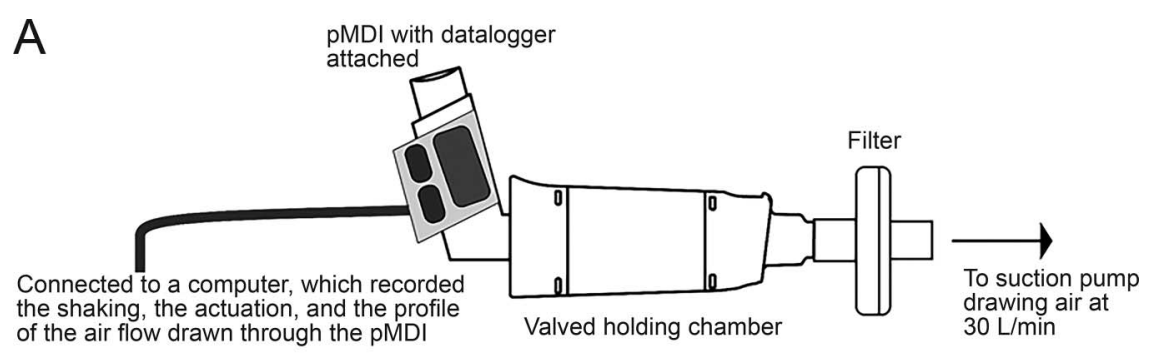

B

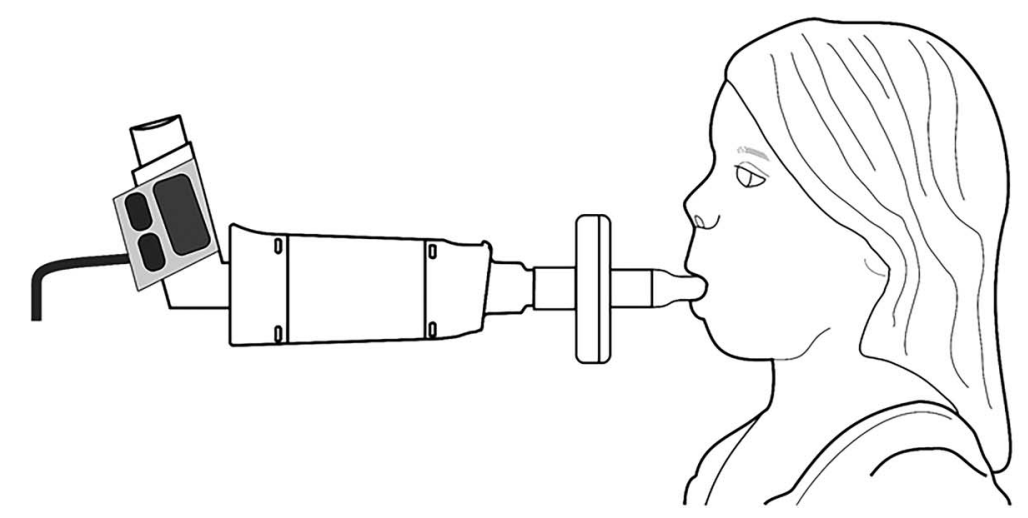

Fig. 1. Experimental setup, in vitro $(A)$ and in vivo $(B)$.

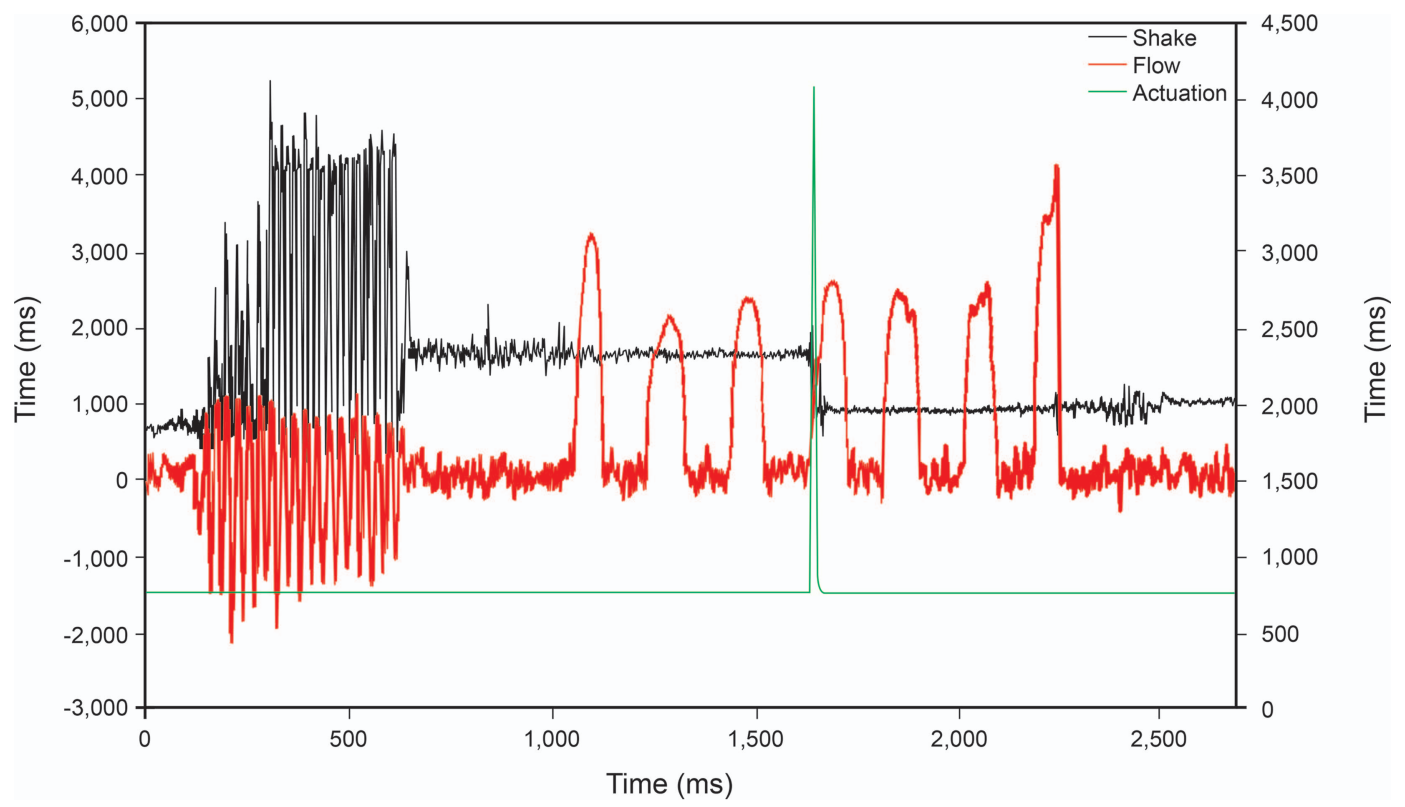

Fig. 2. Example of the tracing obtained from the data logger.

industry standards, and the technicians were blinded to the trial information. ${ }^{5}$ Each participant generated 2 in vitro (pre and post) samples, 3 transport samples, and 6 subject samples.

Thirty-four subjects were randomized (September 26, 2013, to May 1, 2014), and 32 completed the study (mean age [range], 6.4 [5.1-7.9] y old). Fifty-three percent were white, and $63 \%$ were male. Their mean \pm SD height and weight were $119.3 \pm 7.7 \mathrm{~cm}$ and $26.4 \pm 8.6 \mathrm{~kg}$, respectively. The average $(99 \% \mathrm{CI})$ peak inspiratory flow and tidal volume were $23.2(21.3-25.1) \mathrm{L} / \mathrm{min}$ and 281 (251311) $\mathrm{mL}$, respectively. ${ }^{6}$

The emitted dose was calculated as the amount of drug captured in the filter and valved holding chamber of subjects and in vitro samples and in the transport container. Emitted-dose data were expressed as a percentage of the 


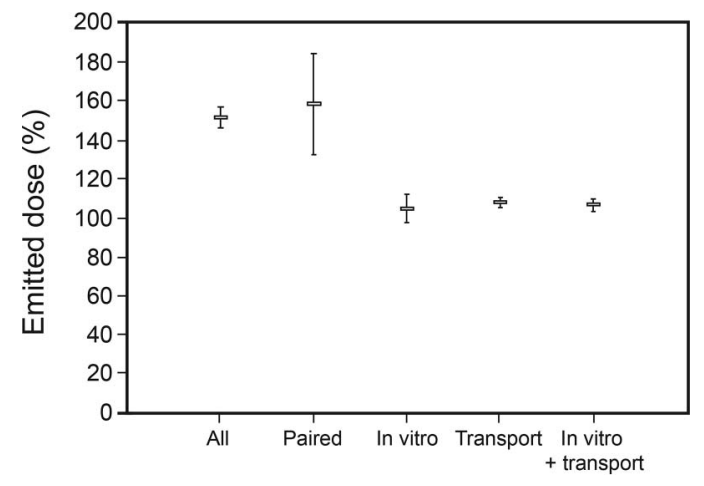

Fig. 3. Emitted dose expressed as percentage of the ex-actuator nominal dose. Markers represent means, and error bars represent $95 \%$ Cls.

ex-actuator nominal dose. Unpaired $t$ test with unequal variances was used to compare emitted dose data from transport and in vitro samples, and from subject and in vitro + transport samples. The time interval between shaking and actuating the pMDI was correlated with emitted dose of the second actuation following the delay for subject data with Spearman correlation. The significance level was established at 0.05 .

\section{Results}

\section{Subjects' Data}

One hundred ninety-two sets of experimental data from subjects were reviewed. There were only 154 pairs of data for emitted dose and time between shaking and actuation. The mean emitted dose data were $151.6 \%$ (95\% CI 144.2 $158.9 \%$ ) (all subject data) and $158.6 \%$ (95\% CI 150.1$167.2 \%$ ) (subject paired data) (Fig. 3).

\section{Experimental Data}

The in vitro data included 64 samples corresponding to 32 subjects and 96 transport samples. The mean emitted dose was $104.9 \%$ (95\% CI $102.4-106.9 \%$ ) and $108 \%$ (95\% CI 104.9-111.2\%) for in vitro and transport control, respectively. There was no difference between the in vitro and the transport samples $(P=.11)$ (Fig. 3). The emitted dose for all subjects' data $($ no. $=192)$ and those with paired interval data $($ no. $=154)$ was significantly bigger than the pooled emitted dose of in vitro + transport controls (no. $=160 ; 106.8 \%$, CI $104.7-108.9 \%, P<.001$ for both). We found a correlation between the time interval between shaking and actuating the pMDI and the emitted dose of the second actuation following the delay.

An increase in time between shaking and actuating the pMDI affected the emitted dose of the second actuation following the delay. A 10-, 20-, and 30-s delay resulted in

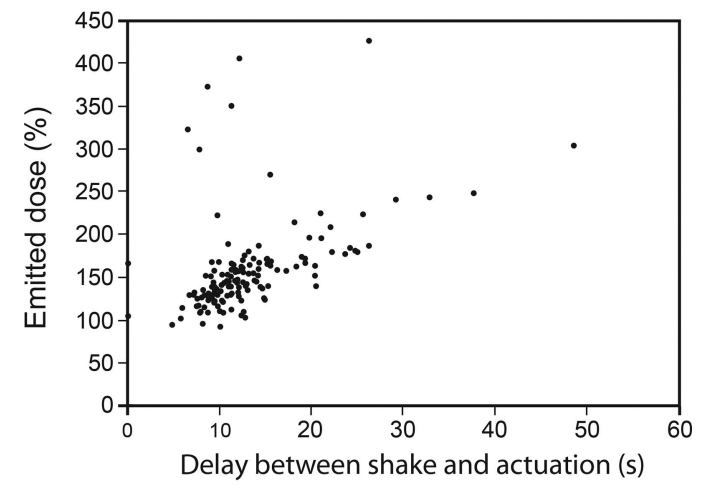

Fig. 4. Correlation of emitted dose of the second actuation following the shaking-actuation delay with interval time between shaking and actuation.

an emitted dose of the second actuation following the delay of 147,187 , and $227 \%$ of the ex-actuator nominal dose, respectively. The Spearman correlation coefficient between the 2 variables was 0.61 (95\% CI $0.51-0.70)$ (Fig. 4). The mean delay between shaking and actuating the pMDI was $12.9 \mathrm{~s}$ (95\% CI 11.9-13.9 s).

\section{Discussion}

We evaluated the effect of a delay between shaking and actuation of a fluticasone suspension pMDI on the emitted dose of the second actuation following the delay. We found that delays of 10,20, and $30 \mathrm{~s}$ resulted in an emitted dose of the second actuation following the delay of 147, 187, and $227 \%$ of the ex-actuator nominal dose, respectively.

Our findings are similar to those of Hatley et al, ${ }^{5}$ who performed an in vitro study evaluating the effect of a delay between shaking and actuating several pMDIs on the emitted dose. Both studies showed that the introduction of a delay between shaking and actuating a fluticasone propionate pMDI resulted in a similar increase in the emitted dose of the second actuation following the delay. The findings in both studies are consistent with settling of drug toward the metering chamber before it replenishes at the time of the actuation. We speculate that this is probably due to the fact that fluticasone particles are denser than the propellant used in the hydrofluoroalkane formulation. ${ }^{7}$

The main limitation of our study is that all data from the emitted dose derived from actuations at the start of life of the pMDI canister, so across canister life effects on emitted dose could not be assessed. The clinical implications of our findings are that if high-dose deliveries were given in the beginning of canister life, then shots toward the end of life would contain little, if any, drug. This phenomenon would lead to variable over- and underdosing, depending on canister life. Thus, if a delay occurs between the time when parents, patients, and practitioners shake the canister and are ready to actuate it, then they should reshake the 


\section{Delay Between Shaking and Actuation of a Suspension pMDI}

pMDI before actuating it. Manufacturers of pMDIs containing drugs formulated as suspensions should specify in their instructions for use the maximum delay time between shaking and actuating that does not significantly affect the emitted dose.

\section{Conclusions}

Delays between shaking and actuating a corticosteroid suspension pMDI resulted in an increase in the emitted dose of the second actuation following the delay to children using a valved holding chamber. This should be addressed by practitioners educating patients and parents on proper inhaler use.

\section{ACKNOWLEDGMENTS}

We acknowledge N. Smith (PS5 Consultants, Portsmouth, United Kingdom) for editorial assistance and preparation of Figure 1.

\section{REFERENCES}

1. Global Strategy for Asthma Management and Prevention. Global Initiative for Asthma (GINA) 2015. http://ginasthma.org/wp-content/ uploads/2016/01/GINA_Report_2015_Aug11-1.pdf. Accessed October 17, 2017.

2. Laube BL, Janssens HM, de Jongh FH, Devadason SG, Dhand R, Diot $\mathrm{P}$, et al. What the pulmonary specialist should know about the new inhalation therapies. Eur Respir J 2011;37(6):1308-1331.

3. Devadason SG, Le Souef PN. Age-associated factors influencing the efficacy of various forms of aerosol therapy. J Aerosol Med 2002; 15(3):343-345.

4. Newman SP. Principles of metered-dose inhaler design. Respir Care 2005;50(9):1177-1190.

5. Hatley RH, Parker J, Pritchard JN, von Hollen D. Variability in delivered dose from pressurized metered-dose inhaler formulations due to a delay between shake and fire. J Aerosol Med Pulm Drug Deliv 2017;30(1):71-79.

6. Berlinski A, von Hollen D, Hatley RHM, Hardaker LEA, Nikander $\mathrm{K}$. Drug delivery in asthmatic children following coordinated and uncoordinated inhalation maneuvers: a randomized crossover trial. J Aerosol Med Pulm Drug Deliv 2017;30(3):182-189.

7. Berg E. In vitro properties of pressurized metered dose inhalers with and without spacer devices. J Aerosol Med 1995;8 (Suppl 3):S3-S10; discussion S11.

This article is approved for Continuing Respiratory Care Education credit. For information and to obtain your CRCE

(free to AARC members) visit www.rcjournal.com 